\title{
RECONSTITUIÇÃO PALEOAMBIENTAL DO QUATERNÁRIO NO ESTUÁRIO DO RIO SANTO ANTÔNIO, ILHA DO MARANHÃO - BRASIL
}

\author{
PALEOENVIRONMENTAL RECONSTITUTION OF THE QUATERNARY IN THE ESTUARY OF \\ RIO SANTO ANTÔNIO, ISLAND OF MARANHÃO - BRAZIL
}

\section{Ana Lucia BIONDO DA COSTA ${ }^{1}$, Leonardo Gonçalves de LIMA ${ }^{\mathbf{1}}$, Claudia KLOSE PARISE ${ }^{1}$, Jorge Hamilton Souza dos SANTOS ${ }^{2}$, André Luis Silva dos SANTOS ${ }^{3}$, Francisco das Chagas de CARVALHO NETO ${ }^{1}$ \\ ${ }^{1}$ Universidade Federal do Maranhão, Departamento de Oceanografia e Limnologia; Laboratório de Estudos em Oceanografia Geológica - LEOG. Emails: anabiondo.costa@gmail.com; lima.leonardo@ufma.br; claudiakparise@gmail.com; carvalhoneto.fmc@gmail.com \\ ${ }^{2}$ Universidade Federal do Maranhão, Departamento de Geociências; Centro de Ciências Humanas. Email: notlimah21@bol.com.br ${ }^{3}$ Instituto Federal do Maranhão- Campus Monte Castelo. Email: andresantos@ifma.edu.br}

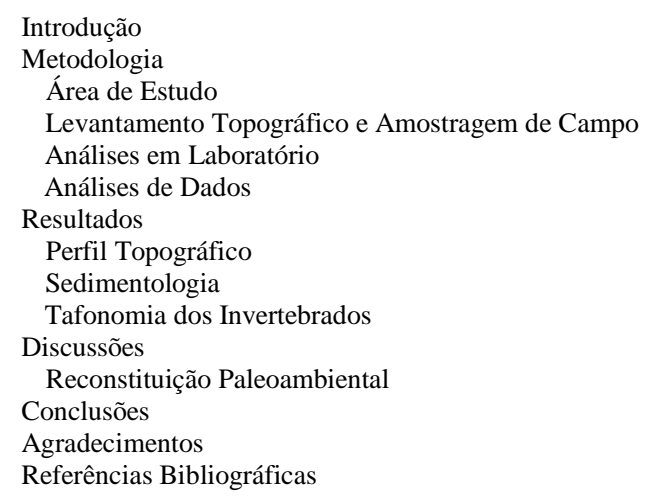

RESUMO - As variações do nível relativo do mar ocorridas durante o Quaternário foram responsáveis pela atual paisagem das zonas costeiras mundiais. Estas alterações seculares do nível do mar, ora transgressivas ora regressivas, deixaram evidências sedimentológicas, estratigráficas, geomorfológicas e paleontológicas que possibilitam a reconstituição paleoambiental desses ambientes. O presente estudo se desenvolveu com base na hipótese de que registros de transgressões e regressões marinhas durante o Quaternário tenham sido preservados na região estuarina do Rio Santo Antônio, extremo leste da Ilha do Maranhão. A partir da interpretação geológica, estratigráfica, sedimentológica e geomorfológica de um afloramento de bioclastos contendo conchas de moluscos bivalves e gastrópodes, foi possível verificar a evidência de um paleonível marinho na margem deste rio. O estudo constatou que os bioclastos acumulados foram resultado de uma condição hidrodinâmica pretérita, provavelmente relacionada ao máximo transgressivo holocênico quando ainda não se fazia presente o esporão arenoso (headlandspit) da Praia de Panaquatira. O mapeamento topográfico do local comprovou que os bioclastos estão situados a $+3,20 \mathrm{~m}$ acima do nível médio do mar. Os resultados obtidos no presente estudo conduziram a uma proposta de reconstituição paleoambiental da área de estudo.

Palavras-chave: Quaternário, paleoambiente, evolução costeira, paleonível marinho.

ABSTRACT - The changes in the relative sea level during the Quaternary were responsible for the conformity of the the coastal zone modern landscape. These secular changes on the sea level, either transgressive or regressive, have left sedimentological, stratigraphic, geomorphological and paleontological evidences which support their paleoenvironmental reconstruction. The present study was based on the hypothesis that Quaternary marine transgressive and regressive records have been preserved in the estuarine region of the Santo Antonio River, in the east boundary of the Maranhão Island. Based on geological, stratigraphy, sedimentological and geomorphological interpretations of a bioclast outcrop containing mollusc shells (bivalve and gastropods), it was possible to verify a marine paleolevel in the river margin. The results have showed that the accumulated bioclasts in the river margin were formed under past hydrodynamic conditions related to the Holocene transgressive maximum, when the Panaquatira headland spit has not been shaped yet. The topographic mapping has situated the bioclast outcrop at $+3.20 \mathrm{~m}$ above the relative sea level. The results obtained in the present study led to a proposal for paleoenvironmental reconstruction of the study area.

Keywords: Quaternary, paleoenvironment, coastal evolution, paleo-sea level.

\section{INTRODUÇÃO}

O Quaternário é um período marcado por mudanças climáticas, as quais resultaram em grandes variações globais nos níveis dos oceanos. De acordo com Curray et al. (1969),
Thom \& Roy (1983) e Meireles et al. (2005) os processos geológicos, geofísicos, geomor.fológicos e climáticos atuais originaram e foram influenciados diretamente pelos diferentes 
níveis do mar durante este período.

$\mathrm{Na}$ costa brasileira ocorreram dois expressivos eventos de transgressão marinha durante o Quaternário: um a 120.000 anos A.P chamado de Penúltima Transgressão, que alcançou um máximo entre +8 e $+10 \mathrm{~m}$ acima do nível médio atual, e outro chamado de Última Transgressão, ocorrida durante o Holoceno, que teria alcançado um máximo de $+5,0 \mathrm{~m}$ acima do atual nível médio do mar a 5.000 anos A.P. (Flexor et al., 1979; Corrêa et al., 1995). Segundo Caldas (2006) na costa norte brasileira o nível relativo do mar alto na Última Transgressão alcançou $+1,4 \mathrm{~m} \quad \mathrm{e}$ quaisquer oscilações de alta frequência e pequena escala ocorridas durante o Holoceno não poderiam ser observadas facilmente, pois a amplitude das marés de hoje são superiores ao nível do mar alto no máximo transgressivo. Os valores de mar alto alcançado no máximo transgressivo no Holoceno citados anteriormente diferenciam-se entre si, porém os resultados dos estudos sobre estas variações mostram um consenso, ao qual definem que o nível do mar atual foi ultrapassado em torno de 7000 anos A.P., e entre 5000 e 6000 anos A.P. ocorreu o máximo transgressivo, sendo alguns metros acima do nível médio do mar atual (Caron et al., 2011).

Estas alterações seculares do nível do mar de naturezas eustáticas ou isostática representam o principal agente transformador da paisagem na zona costeira. Segundo Curray (1964) quando a linha de costa migra em direção ao continente ocorre à transgressão marinha e no inverso ocorre à regressão marinha, quando à linha de costa migra em direção ao centro da bacia oceânica.

O avanço da linha de costa sobre o continente interioriza as feições costeiras, e no recuo as feições costeiras avançam sobre a plataforma continental, deixando para trás as evidências sedimentológicas, estratigráficas, geomorfológicas e paleontológicas de feições costeiras existentes no período do mar alto, onde o conjunto de informações obtidas através dessas evidências podem gerar um bom modelo paleoambiental.

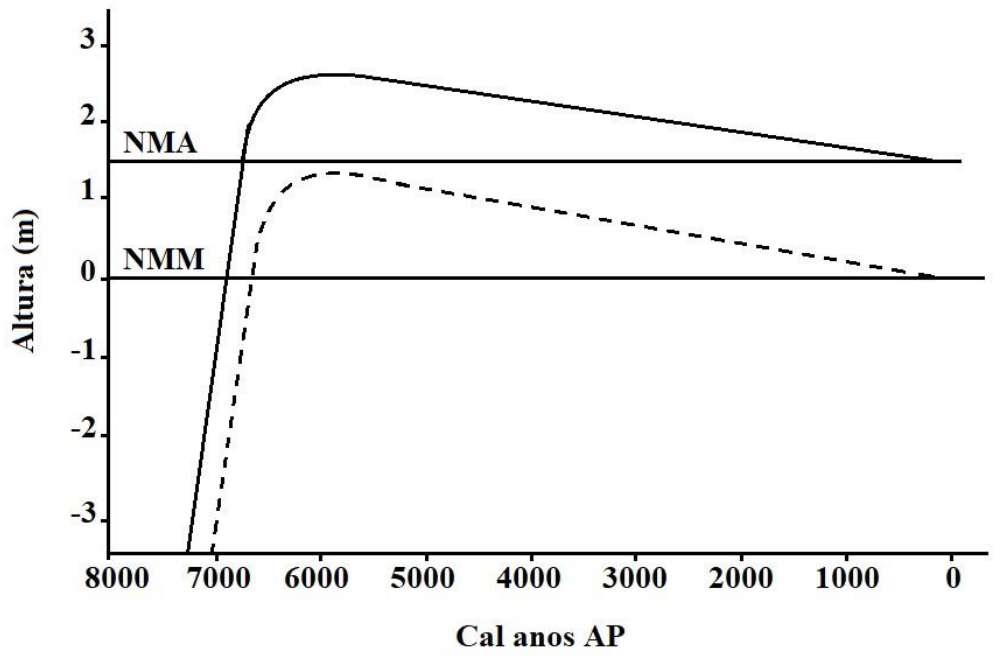

Figura 1 - Curva envelope de variação do nível do mar para o Rio Grande do Norte. NMA - nível da maré alta atual e NMM - nível da maré média atual. Fonte: Adaptado de Caldas et al. (2006).

A ilha do Maranhão situa-se que possui como unidades estratigráficas a aproximadamente no centro de um grande Formação Alcântara, Barreiras e Açuí sistema estuarino denominado Golfão Mara- (Rodrigues et al., 1994; Almeida, 2000; Veiga nhense. Conforme Santos et al. (2004), no Júnior, 2000; Pereira, 2006; Pereira \& Zaine, referido Golfão de origem Pleistocênica, tem- 2007). Grande parte da ilha do Maranhão se a presença de baías, estuários estreitos, igarapés, enseadas, ilhas, falésias, pontais rochosos, praias de areia quartzosas, dunas e planícies de maré. A geologia da ilha corresponde à bacia sedimentar de São Luís, possui formações sedimentares suscetíveis à erosão (Pereira \& Zaine, 2007). Esta erosão se processa de forma mais ou menos intensa dependendo da origem e evolução do segmento litoral em que se encontra. 
A evolução costeira que se seguiu desde a Última Transgressão Marinha Pós-Glacial destruiu grande parte dos registros Quaternários, bem como as evidências sedimentológicas e paleontológicas de variações do nível do mar contidas neles (Belknap \& Kraft, 1985; Cowell et al., 1999). São raros os ambientes deposicionais costeiros remanescentes deste período que não foram perdidos em função da dinâmica costeira, principalmente devido ao condicionamento geológico regional, que expõe os registros sedimentares do Mioceno.

As diferentes paisagens da ilha do Maranhão são resultado da fragilidade das estruturas geológicas e da exposição aos agentes modeladores do relevo, como os de origem climática, hidrológica e oceanográfica (Feitosa, 2013). A gênese deste litoral decorre de uma situação de déficit de sedimentos no prisma costeiro expondo antigas formações em praticamente toda a extensão deste litoral. $\mathrm{O}$ sistema de barreiras costeiras enquadra-se no tipo praias anexadas (mainland beach barrier) existindo ainda nos limites dos promontórios com os sistemas fluviais um contexto de esporões arenosos (headland spit barrier) (e.g. Cowell \& Thom, 1994; Roy et al., 1994). Este modelamento litorâneo destruiu grande parte dos registros sedimentológicos quaternários na ilha do Maranhão resguardando uma pequena quantidade de registros somente nas posições mais recortadas deste litoral. $\mathrm{O}$ presente estudo procurou responder com base na evolução do paleoambiente deposicional costeiro, como estas evidências foram preservadas.

\section{MÉTODOS}

\section{Área de Estudo}

A área de estudo encontra-se na região estuarina do Rio Santo Antônio (extremo leste da Ilha do Maranhão) (2`31'37,72”S $44^{\circ} 05^{\prime} 03,88^{\prime}$ 'O), há $10 \mathrm{~km}$ de distância da foz, mais precisamente na comunidade de Pau Deitado no município de São José de Ribamar (Figura 2). O objeto deste estudo é um terraço de abrasão marinha esculpido por ação de ondas em rochas sedimentares da formação Itapecuru sobre o qual se encontra um acúmulo de material bioclástico.

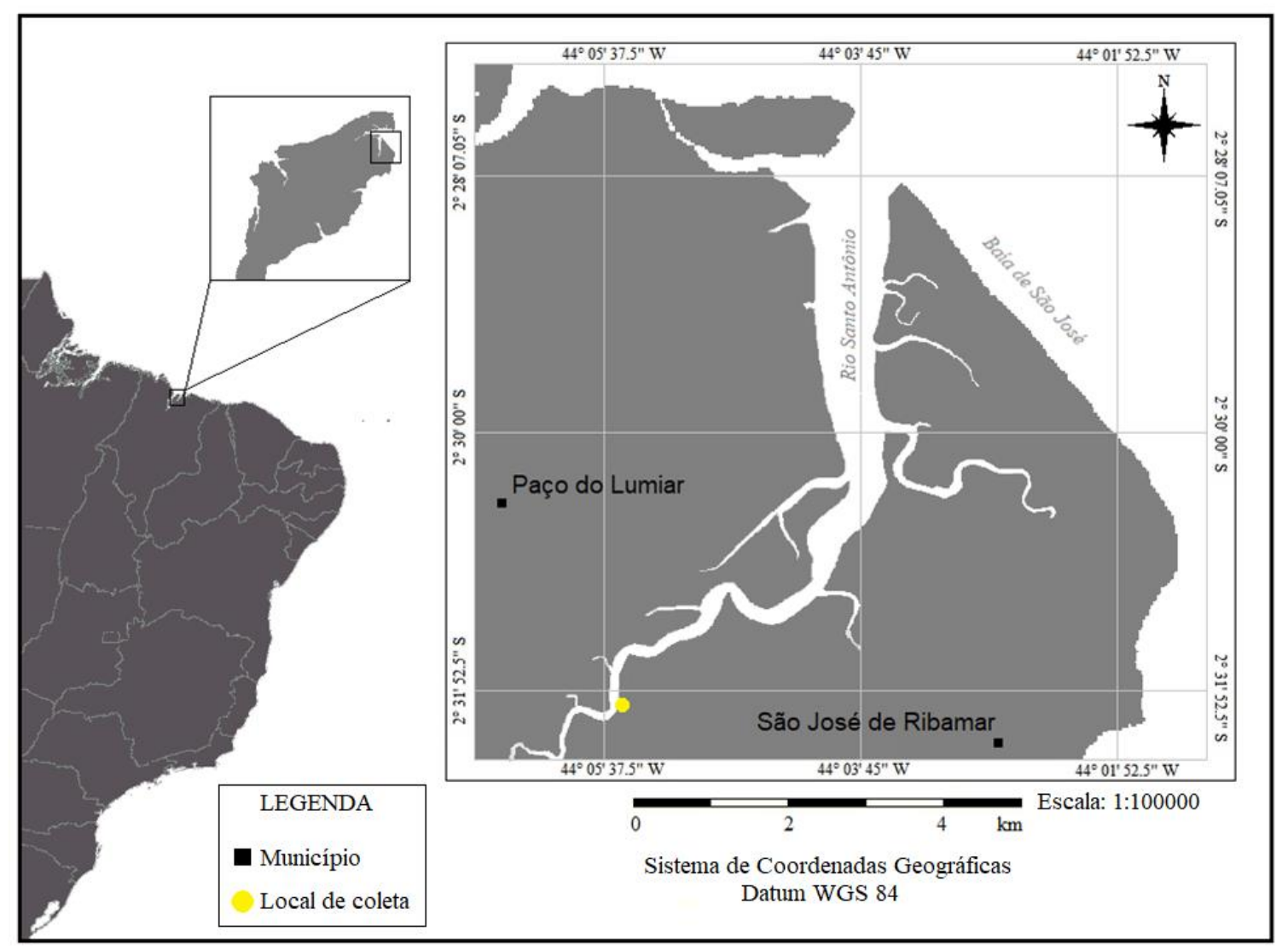

Figura 2 - Mapa de localização da área de estudo mostrando o local de coleta no Rio Santo Antônio, processado no Software QGis 2.12 Lyon. Fonte: Elaborado por Costa, A.B. (2017) a partir de bases de dados disponibilizados pelo IBGE (2016). 


\section{Levantamento Topográfico e Amostragem de Campo}

O levantamento topográfico foi realizado utilizando-se um nível topográfico CST/Berger no sentido (leste-oeste) continente - lâmina d'água do Rio Santo Antônio, de forma a cruzar transversalmente a margem na qual se encontra o terraço de abrasão marinha com os bioclastos.

Para o posicionamento de precisão do afloramento contendo os bioclástos foi utilizado um GPS geodésico, modelo Trimble R4 de frequência L1 e L2, onde foi utilizado o método estático rápido, com um tempo de medição de duas horas.

A amostragem de sedimentos do afloramento buscou caracterizar as fácies que delimitavam a porção contendo bioclastos sendo assim foram amostrados cinco níveis estratigráficos $(\mathrm{N} 1, \mathrm{~N} 2$, N3, N4 e N5) separados por características observáveis das fácies sedimentares do terraço (como por exemplo, a cor), onde N5 é o nível acima do afloramento, o N4 o nível de topo, o N3 o nível da base dos bioclastos; N2 nível da base do terraço erodido pela maré alta e N1 nível na base do terraço na maré baixa.

A análise tafônomica foi realizada a partir da remoção de um bloco intacto da fácies $\mathrm{N} 4$, de dimensões $35 \times 25 \times 15 \mathrm{~cm}$. Foram também efetuados anotações e registros fotográficos para caracterizar a área de estudo, os detalhes dos afloramentos encontrados e os procedimentos de coleta. O material coletado em campo foi estocado no LEOG - Laboratório de Estudos em Oceanografia Geológica no DEOLI- Departamento de Oceanografia e Limnologia da Universidade Federal do Maranhão.

\section{Análises em Laboratório}

Em laboratório, foi realizada a classificação de cor das amostras sedimentares segundo Munsell (2009). Cada nível sedimentar foi seco em estufa a $60^{\circ} \mathrm{C}$ e desagregados em almofariz de porcelana e quarteados. A determinação de carbonato foi realizada por gravimetria a partir de alíquotas de $20 \mathrm{~g}$ de cada nível sedimentar, adicionando-se $\mathrm{HCl}$ a $10 \%$ por 24 horas.

O teor de matéria orgânica heterogênea foi obtido a partir do método proposto por Wetzel (1993), de perda de massa por ignição, onde alíquotas de $5 \mathrm{~g}$ de sedimento foram calcinadas em forno de Lavoisier, a $550^{\circ} \mathrm{C}$ durante 4 horas.

As análises granulométricas seguiram a método descrito em Suguio (1973), utilizando-se intervalos de $1 / 2$ Phi. A partir dos resultados da peneiragem e pipetagem os dados foram processados no software SYSGRAN ${ }^{\circledR}$ (Camargo, 2006), segundo o processamento estatístico de Folk \& Ward (1957). A moda granulométrica das fácies (N1, N2, N3, N4 e N5) foi avaliada segundo análise morfoscópica de 100 grãos, sendo classificados segundo o grau de arredondamento, esfericidade e textura superficial, seguindo a metodologia de Krumbein (1941); Bigarella (1955) e Rittenhouse (1943), respectivamente.

O nível N4 foi lavado e processado em peneira de malha $0,5 \mathrm{~mm}$, onde os bioclastos foram separados do resto do material sedimentar para avaliação tafonômica, segundo Holz \& Simões (2002) e classificação taxonômica de acordo com Abbott (1974). Para cada concha foi avaliada seis tipos de assinaturas tafonômicas descritas por Ponciano (2015), desarticulação, fragmentação, desgaste químico, desgaste físico, incrustação e bioturbação.

Para caracterizar a intensidade da ação destas assinaturas foi elaborada uma ficha de classificação onde foram atribuídas as seguintes categorizações: não atuante (0) quando as ornamentações das conchas eram facilmente observadas; pouco atuante (1) quando uma ou duas assinaturas estavam presentes na concha, porém a valva não apresentava perdas significativas de ornamentações características de cada gênero; atuante (2) era atribuída às conchas nas quais a assinatura identificada havia avariado boa parte das ornamentações e estruturas de identificação das conchas e ou era perceptível a ação de três ou mais assinaturas; o fichamento como muito atuante (3) era dado para conchas afetadas por completo pela ação da assinatura tafonômica, ou seja, impossibilitava a identificação. (Figura 3).

A geometria deposicional dos bioclastos foi classificada em planos de acamamento, em secção e posicionamento das valvas, onde ao se desenterrar o bloco, os horizontes foram fotografados e as posições das valvas aferidas com o auxílio de uma régua transferidor. Seus valores foram anotados por horizonte "descascado" e as angulações corrigidas com o ângulo original do bloco no afloramento (Figura 4).

O mapeamento do estuário do Rio Santo Antônio foi realizado a partir do tratamento de imagens SRTM da National Aeronautics and Space Administration (NASA), imagens orbitais 
do Google Earth, e satélite Systéme Probatoire de l'Observation de la Terre (Spot 1), disponíveis pelo United States Geological Survey (USGS) e pelo Instituto Nacional de Pesquisas Espaciais (INPE), com o software QGis 2.12 Lyon, Google Earth Pro e o Global Mapper v16.1

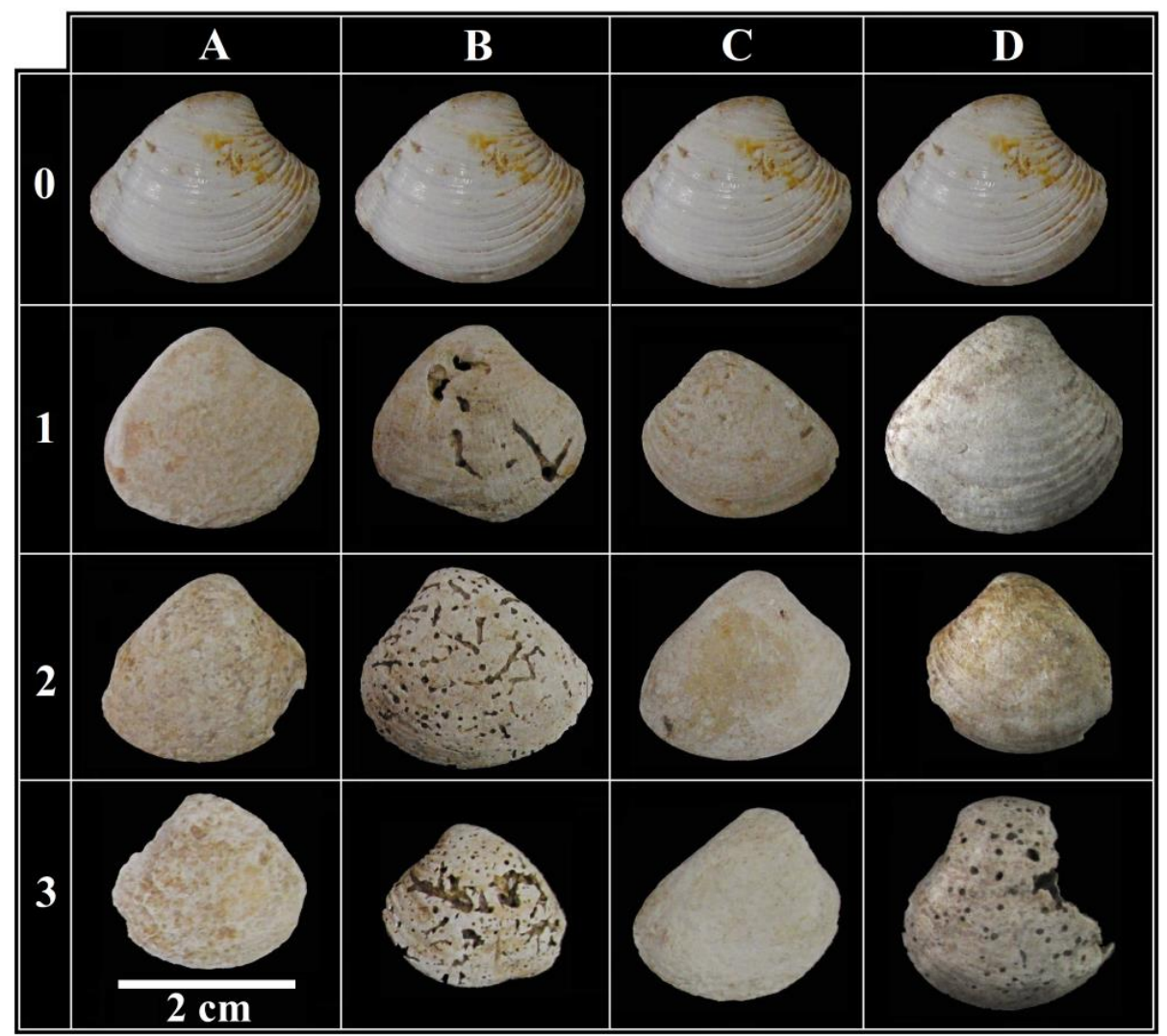

Figura 3 - Exemplo da intensidade de ação de 4 das 6 assinaturas tafonômicas analisadas nas amostras. Onde: A- Desgaste Químico; B- Bioerosão; C- Desgaste Físico e D- Fragmentação.

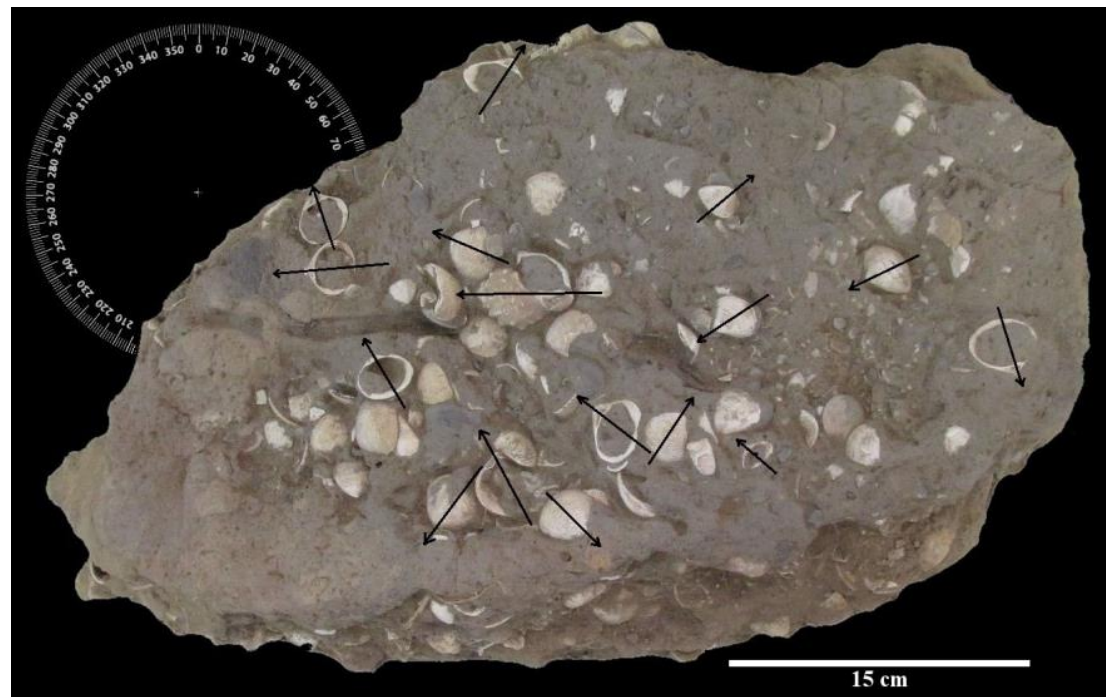

Figura 4 - Método de análise do posicionamento das conchas no bloco amostrado. As setas indicam o sentido deposicional da concha levando em consideração o sentido para onde o umbo das valvas estava direcionado.

\section{RESULTADOS}

O estuário do Rio Santo Antônio encontra-se confinado numa ria de cerca de $500 \mathrm{~m}$ de largura, onde $90 \%$ de sua área encontra-se tomada por terraços de maré, ocupados por vegetação de mangue das espécies Rhizophora mangle, Laguncularia racemosa, Avicennia schaueriana.

A calha fluvial e os sistemas de igarapés 
encurtam-se gradativamente ao distanciar-se da foz onde estão presentes depósitos marinhos litorâneos e depósitos flúvio-marinhos constituídos por silte arenoso, plástico, não adensado, maciço e intensamente bioturbado por Mytella charruana. O terraço de abrasão marinha sobre o qual se encontra o afloramento bioclástico situa-se na margem da ria do Rio Santo Antônio. Ele está localizado numa projeção da margem, especificamente num segmento erosivo de um meandro. Esta projeção serve como área portuária para pequenas embarcações artesanais da região.

Esta margem erosiva encontra-se esculpida sobre a Formação Itapecuru sendo composta por siltitos e folhelhos vermelhos classificados como silte grosso (phi 8) muito pobremente selecionado, coeso, com estratificação planoparalela e processos de ferruginização e caulinização. $\mathrm{O}$ afloramento em si é representado pelas fácies N3, N4 e N5 inseridas discordantemente sobre um terraço de abrasão na Formação Itapecuru (fácies $\mathrm{N} 1$ e N2). (Figura 5).
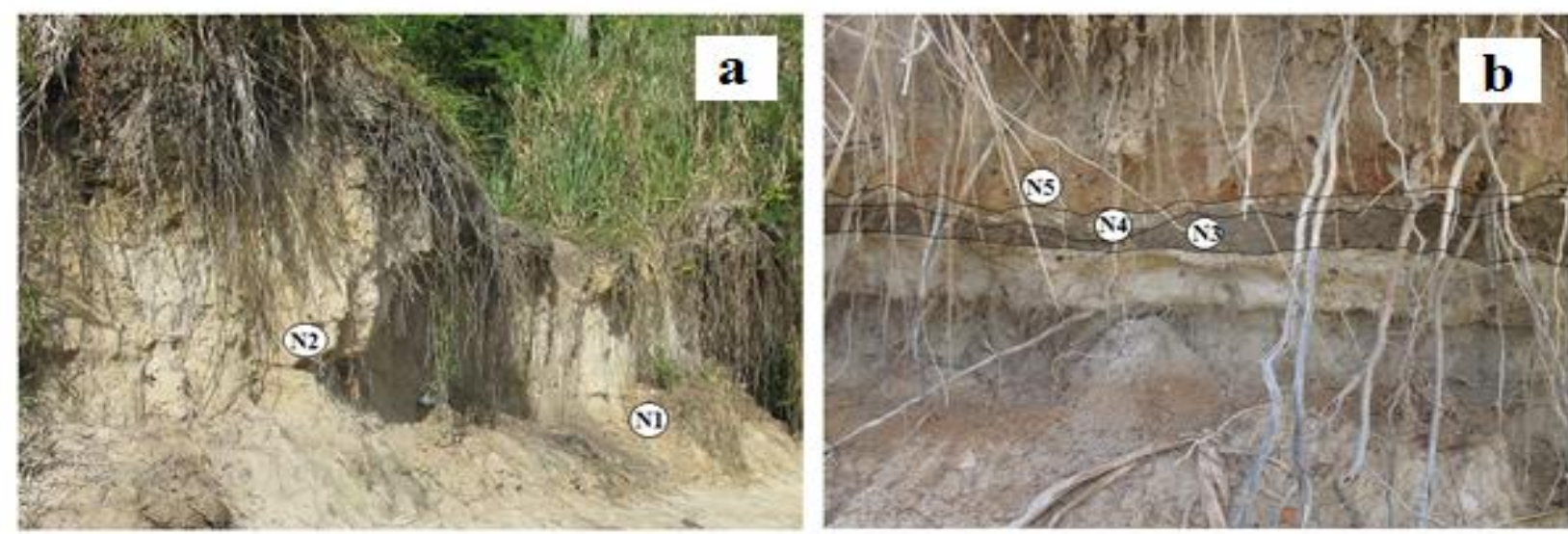

Figura 5 - Fácies N1, N2, N3, N4 e N5 amostrados do terraço de abrasão marinha na região do Rio Santo Antônio onde afloram: (a) Formação Itapecuru; (b) níveis relacionados ao acúmulo de bioclastos.

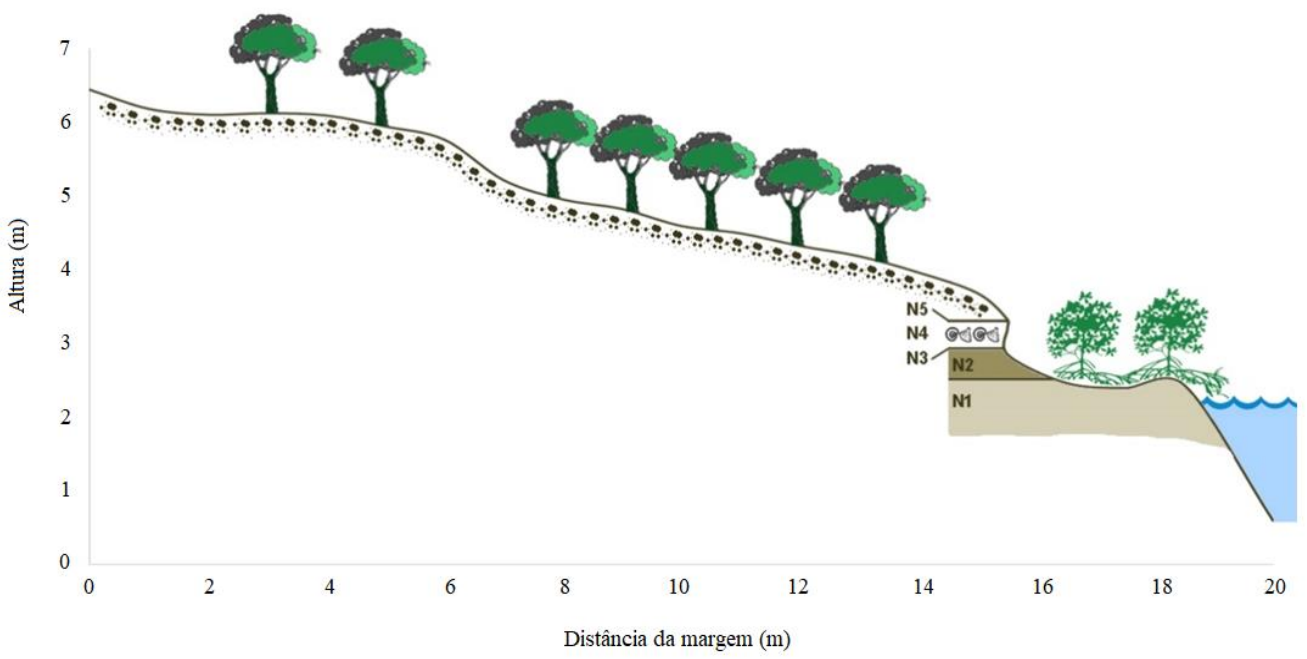

Figura 6 - Perfil topográfico/estratigráfico do afloramento. N1 a N5 indicam as fácies sedimentares.

O nível estratigráfico contendo bioclastos de moluscos estende-se por 3 metros ao longo da margem, sendo constantemente pisoteado nos pontos de acesso as embarcações. $O$ terraço apresenta um desnível acentuado de 6,5 metros entre topo da Formação Itapecuru e a lâmina d'água. $\mathrm{O}$ afloramento encontra-se na cota $+3,2$ m (Figura 6), a mesma cota atingida pelas marés de sizígia equinociais.

A análise granulométrica evidenciou a similaridade entre as fácies $\mathrm{N} 1$ e N2, sendo os grãos predominantemente mais finos do que aqueles das fácies $\mathrm{N} 3, \mathrm{~N} 4$ e N5, expressa no gráfico de frequência acumulada das cinco fácies (Figura 7) assim como pela classificação verbal (Tabela 1). 


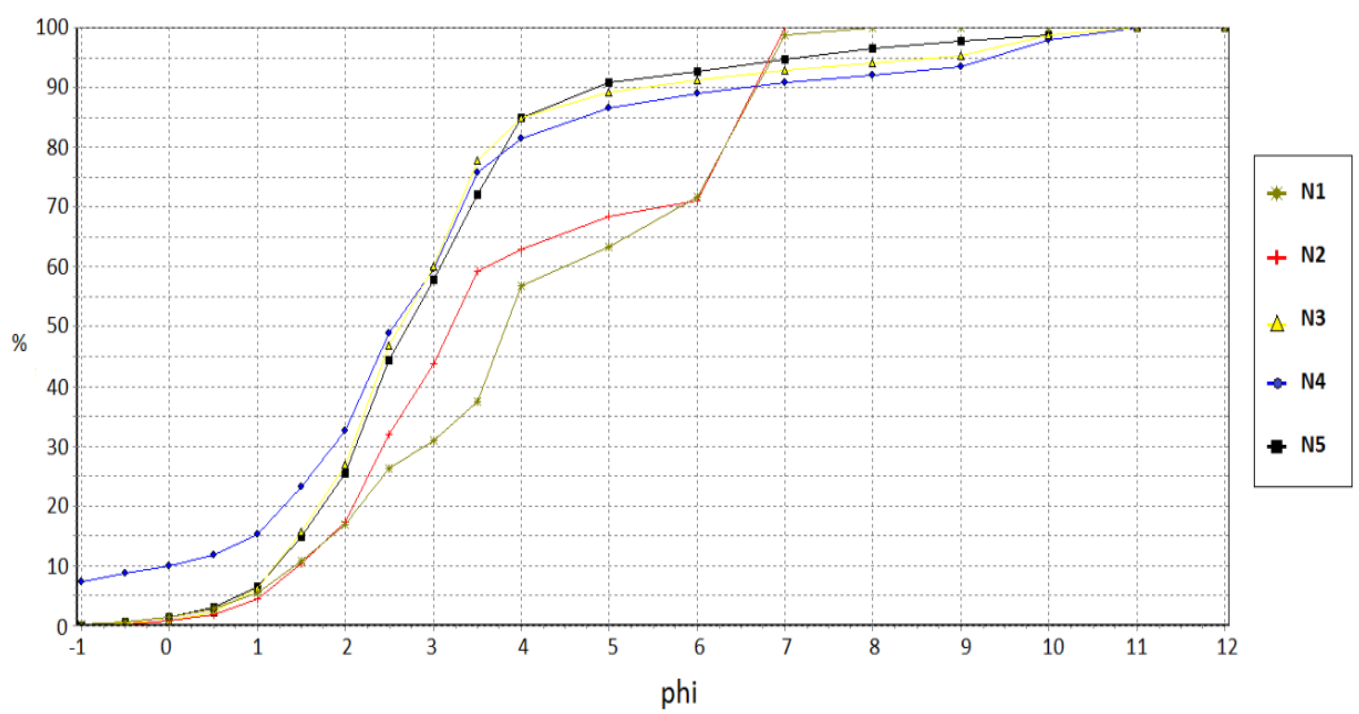

Figura 7 - Frequência acumulada do tamanho dos grãos em phi das fácies sedimentares do terraço de abrasão marinha contendo bioclastos.

Tabela 1 - Classificação das cinco amostras de acordo com: média granulométrica, seleção assimetria e curtose.

\begin{tabular}{c|c|c|c|c}
\hline \multirow{2}{*}{ AMOSTRAS } & \multicolumn{4}{|c}{ CLASSIFICAÇÃO VERBAL } \\
\cline { 2 - 5 } N1 & Média & Seleção & Assimetria & Curtose \\
\hline N2 & Areia muito fina & $\begin{array}{c}\text { Muito pobremente } \\
\text { selecionado } \\
\text { selecionado }\end{array}$ & $\begin{array}{c}\text { Aproximadamente } \\
\text { simétrica }\end{array}$ & Muito platicúrtica \\
\hline N3 & Areia fina & $\begin{array}{c}\text { Pobremente } \\
\text { selecionado }\end{array}$ & Muito positiviva & Muito platicúrtica \\
\hline N4 & Areia fina & $\begin{array}{c}\text { Muito pobremente } \\
\text { selecionado }\end{array}$ & Positiva & Muito leptocúrtica \\
\hline N5 & Areia fina & $\begin{array}{c}\text { Pobremente } \\
\text { selecionado }\end{array}$ & Positiva & Muito leptocúrtica \\
\hline
\end{tabular}

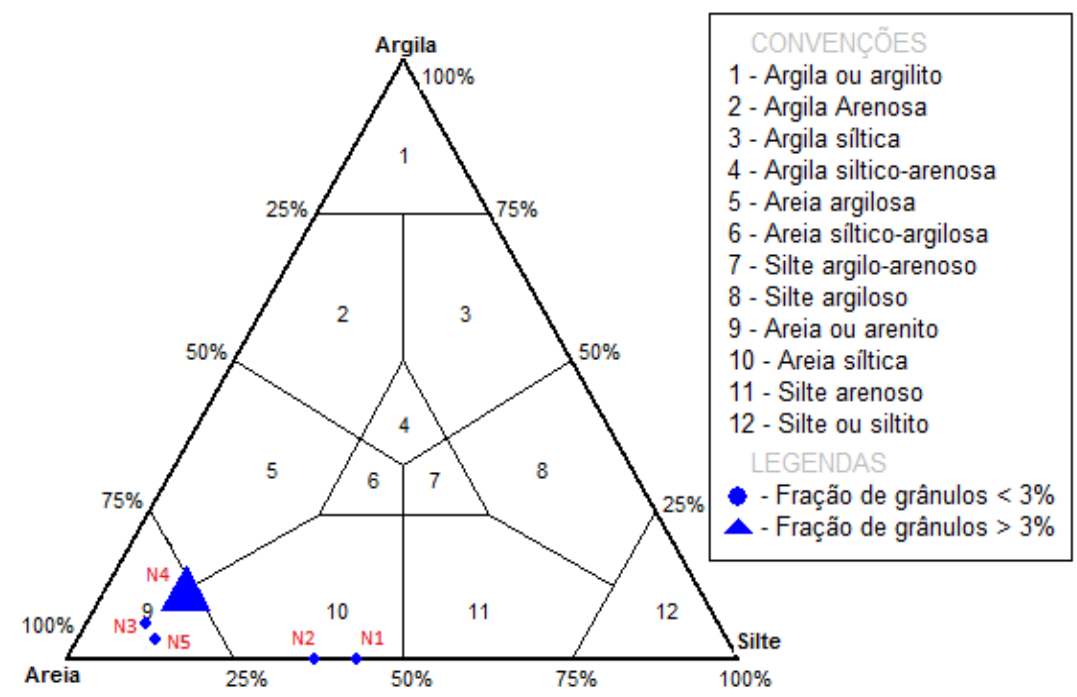

Figura 8 - Diagrama de Shepard mostrando a granulometria predominante das amostras N1 a N5.

Utilizando-se um diagrama de Shepard (Figura 8) as fácies $\mathrm{N} 1$ e N2 foram classificadas como areia síltica, característica da composição da Formação Itapecuru do Cretáceo, e as fácies N5, N4 e N3 como areia fina, característicos dos depósitos areno-lamosos do Quaternário, presentes na região.

As porcentagens de tamanhos de grãos nas cinco fácies (Tabela 2) demonstram novamente à similaridade entre N1 e N2 onde não foi 
verificada a fração argilosa (Figura 5a). As fácies N3, N4 e N5 apresentaram principalmente a fração areia. A amostra N4 destoa das demais com relação à fração cascalho, devido à grande concentração de bioclastos associada a ela (Figura 5b) assim como é a de maior porcentagem argilosa, essa característica pode indicar um momento de baixa energia do ambiente.

A fácies N1 apresentou a maior concentração de grãos finos, sendo classificada como silte grosso, muito pobremente selecionado. A média do tamanho dos grãos foi de phi 4,0. Quanto à assimetria foi classificada como aproximadamente simétrica e quanto à curtose, muito platicúrtica (Tabela 1). A sua cor foi classificada como moderadamente laranjaavermelhado (10R 6/6). A porcentagem de matéria orgânica foi de $2 \%$ e de carbonatos de $3 \%$ (Tabela 3).

Tabela 2 - Valores percentuais obtidos para o tamanho dos grãos das amostras N1 a N5.

\begin{tabular}{c|c|c|c|c}
\hline AMOSTRAS & $\begin{array}{c}\text { Cascalho } \\
\mathbf{\%}\end{array}$ & $\begin{array}{c}\text { Areia } \\
\mathbf{\%}\end{array}$ & $\begin{array}{c}\text { Silte } \\
\mathbf{\%}\end{array}$ & $\begin{array}{c}\text { Argila } \\
\mathbf{\%}\end{array}$ \\
\hline $\mathbf{N 1}$ & 0,1 & 56,8 & 43,1 & 0,0 \\
\hline $\mathbf{N 2}$ & 0,1 & 62,9 & 37,0 & 0,0 \\
\hline $\mathbf{N 3}$ & 0,1 & 84,9 & 9,1 & 5,9 \\
\hline $\mathbf{N 4}$ & 7,4 & 74,1 & 10,5 & 8,0 \\
\hline $\mathbf{N 5}$ & 0,1 & 85,0 & 11,6 & 3,4 \\
\hline
\end{tabular}

Tabela 3 - Percentuais de matéria orgânica e carbonatos encontrados nas fácies sedimentares.

\begin{tabular}{c|c|c}
\hline AMOSTRAS & $\begin{array}{c}\text { Matéria } \\
\text { Orgânica \% }\end{array}$ & $\begin{array}{c}\text { Carbonatos } \\
\%\end{array}$ \\
\hline N1 & 8 & 3 \\
\hline N2 & 2 & 1 \\
\hline N3 & 1 & 2 \\
\hline N4 & 2 & 26 \\
\hline N5 & 2 & 3 \\
\hline
\end{tabular}

Com base na análise de morfoscopia desta fácies foi possível notar a predominância de grãos lateríticos (cerca de 50\%), grãos de quartzo recapeados com óxido de ferro $(\mathrm{FeO})$ (4\%) e grãos quartzosos sem recapeamento (46\%), em sua maioria arredondados (43\%) e bem arredondados (36\%), moderadamente esféricos (35\%) e com textura superficial predominante lisa polida (53\%) (Tabela 4).

A fácies N2 foi classificada como areia muito fina, muito pobremente selecionada, tendo assimetria muito positiva e sendo também muito platicúrtica (Tabela 1).

A média do tamanho dos grãos foi de phi 3,8 . Semelhante a amostra N1, a porcentagem de matéria orgânica foi de $2 \%$ e de carbonatos de 3\% (Tabela 3). O material separado para a morfoscopia apresentou a moda com fração granulométrica siltosa, impossibilitando a análise na lupa, sendo assim não foram classificados o grau de arredondamento, esfericidade ou textura superficial da amostra (Tabela 4). A cor foi classificada como cinzaoliva claro (5Y 6/1).

Tabela 4 - Resultado da morfoscopia das fácies. Onde: B.arr- Bem arredondado, Arr- Arredondado, Sub-arr-Subarredondado, Sub-ang-Sub-angular, Ang- Angular, B. esf- Bem esférico, M. esf- Moderadamente esférico, P. esf- Pouco esférico, Along- Alongado, L. polido- Liso polido, L. fosco- Liso fosco, M. liso- Mamelonado liso, M. foscoMamelonado fosco, Sac-Sacaróide.

\begin{tabular}{|c|c|c|c|c|c|c|c|c|c|c|c|c|c|c|}
\hline \multirow[b]{2}{*}{ AMOSTRAS } & \multicolumn{5}{|c|}{ ARREDONDAMENTO (\%) } & \multicolumn{4}{|c|}{ ESFERICIDADE (\%) } & \multicolumn{5}{|c|}{ TEXTURA SUPERFICIAL (\%) } \\
\hline & $\begin{array}{c}\text { B. } \\
\text { arr }\end{array}$ & $A r r$ & $\begin{array}{c}\text { Sub- } \\
\text { arr }\end{array}$ & $\begin{array}{c}\text { Sub- } \\
\text { ang }\end{array}$ & Ang & $\begin{array}{l}B . \\
e s f\end{array}$ & $\begin{array}{l}M . \\
\text { esf }\end{array}$ & $\begin{array}{l}P . \\
\text { esf }\end{array}$ & Along & $\begin{array}{c}\text { L. } \\
\text { polido }\end{array}$ & $\begin{array}{c}L . \\
\text { fosco }\end{array}$ & $\begin{array}{c}\text { M. } \\
\text { liso }\end{array}$ & $\begin{array}{c}M . \\
\text { fosco }\end{array}$ & $\overline{S a c}$ \\
\hline N1 & 32 & 43 & 21 & 4 & 0 & 18 & 35 & 29 & 18 & 53 & 32 & 10 & 2 & 3 \\
\hline $\mathbf{N} 2$ & - & - & - & - & - & - & - & - & - & - & - & - & - & - \\
\hline N3 & 30 & 47 & 19 & 4 & 0 & 23 & 40 & 29 & 8 & 50 & 36 & 11 & 2 & 1 \\
\hline N4 & 25 & 41 & 22 & 12 & 0 & 9 & 26 & 46 & 19 & 61 & 25 & 10 & 3 & 1 \\
\hline N5 & 25 & 38 & 20 & 15 & 2 & 12 & 39 & 21 & 28 & 50 & 36 & 8 & 2 & 4 \\
\hline
\end{tabular}


A fácies N3 apresentou o nível de cor mais escura em comparação com as demais, classificada como castanho acinzentado (5Y $3 / 2$ ). A média do tamanho dos grãos foi $p h i$ 2,6, classificada como areia fina, pobremente selecionada, de assimetria muito positiva e, diferente das amostras $\mathrm{N} 1$ e N2, foi classificada como muito leptocúrtica (Tabela 1). A quantidade de matéria orgânica foi de1\%e de carbonatos foi de $2 \%$ (Tabela 3 ). Cerca de $47 \%$ dos grãos foram classificados como arredondados e $30 \%$ como bem arredondados. Quanto à esfericidade foram classificados como moderadamente esféricos $(40 \%)$ e de textura superficial lisa polida (50\%), (Tabela 4).

A fácies $\mathrm{N} 4$ apresentou $2 \%$ de matéria orgânica e $26 \%$ de carbonatos em sua composição (Tabela 3), a maior concentração de carbonatos dentre todas as amostras analisadas. Foram encontrados também fragmentos de carvão com diâmetros inferiores a $2 \mathrm{~mm}$.

Quanto à morfoscopia a maioria dos grãos foi classificada como: arredondados (41\%), pouco esféricos (46\%) e com textura superficial predominante lisa polida (61\%) (Tabela 4). Das cinco fácies, a N4 foi a que apresentou a maior concentração de cascalho, devido à presença dos fragmentos de conchas, no entanto foi classificada como sendo predominantemente areia fina, muito pobremente selecionada, de assimetria positiva e curtose muito leptocúrtica (Tabela 1). A média do tamanho dos grãos foi de phi 2,6 e a cor foi classificada como laranja acinzentada (10YR 7/4).

A fácies N5 apresentou fragmentos de carvão de diferentes tamanhos, variando entre 2 a 30 milímetros de diâmetro, sua cor foi classificada como marrom amarelada (10YR 5/4). A porcentagem de matéria orgânica foi de $2 \%$ e de carbonatos de $3 \%$ (Tabela 3 ). Os resultados de morfoscopia (Tabela 4) mostraram que a análise do arredondamento classificou a maioria dos grãos (38\%) como sendo arredondados, quanto à esfericidade dos grãos 39\% foram considerados moderadamente esféricos e a textura superficial foi predominante lisa, apresentando50\% polida e $36 \%$ fosca. A análise granulométrica da amostra N5 indicou uma composição predomi- nantemente de areia fina, sendo um sedimento pobremente selecionado, de assimetria positiva e curtose muito leptocúrtica (Tabela 1), com média do tamanho dos grãos de phi 2,7. As análises tafonômicas foram realizadas em 591 espécimes de bioclástos, pertencentes a mais de um tipo de táxon. A maioria dos espécimes foi classificada como animais pertencentes ao Filo Mollusca, predominantemente da Classe Bivalvia, de ambiente marinho ou marinho/estuarino. Apenas um animal foi classificado como sendo de um filo diferente, pertencente ao Filo Bryozoa, também de ambiente marinho.

Os indivíduos analisados encontravam-se completamente desarticulados, algumas valvas apresentavam ornamentações típicas dos gêneros preservados. Conchas frágeis, como a do gênero Tagelus apresentavam-se em um bom estado de preservação, outras estavam completamente fragmentadas ou desgastadas. Cerca de $5 \%$ dos exemplares de Anomalocardia brasiliana foram encontrados com marcas de perfurações feitas por predadores, que podem estar associadas com os gastrópodes da família Thaididae (Figura 9). A maioria de indivíduos encontrados foi da espécie Anomalocardia brasiliana, representando $77 \%$ do total de indivíduos, considerada a espécie mais repre-sentativa no afloramento. As classes de tamanho entre os indivíduos variaram de 4 a $32 \mathrm{~mm}$.

A fácies $\mathrm{N} 4$ foi hierarquizada em seis horizontes $(\mathrm{a} ; \mathrm{b} ; \mathrm{c} ; \mathrm{d} ; \mathrm{e} ; \mathrm{f})$ à medida que se removiam níveis sucessivos de deposição. Segundo a orientação em plano dos indivíduos do bloco amostrado, esta foi classificada como polimodal, isto é, as conchas estavam orientadas em vários ângulos. A distribuição posicional das valvas foi aferida em $51,5 \%$ de indivíduos com a concavidade voltada para baixo e 48,5\% para cima. A orientação em secção apresentou tendência concordante, porém ocorreram bioclastos aninhados ou oblíquos. Os horizontes (d) e (e) foram os mais adensados e apresentaram rizoconcreções, que reposicionaram as conchas nas suas proximidades.

Após o horizonte (f), os bioclastos desapareceram e uma camada, de aproximadamente três centímetros de sedimento, separou um segundo nível contendo bioclastos completamente fragmentados (Figura 10). 


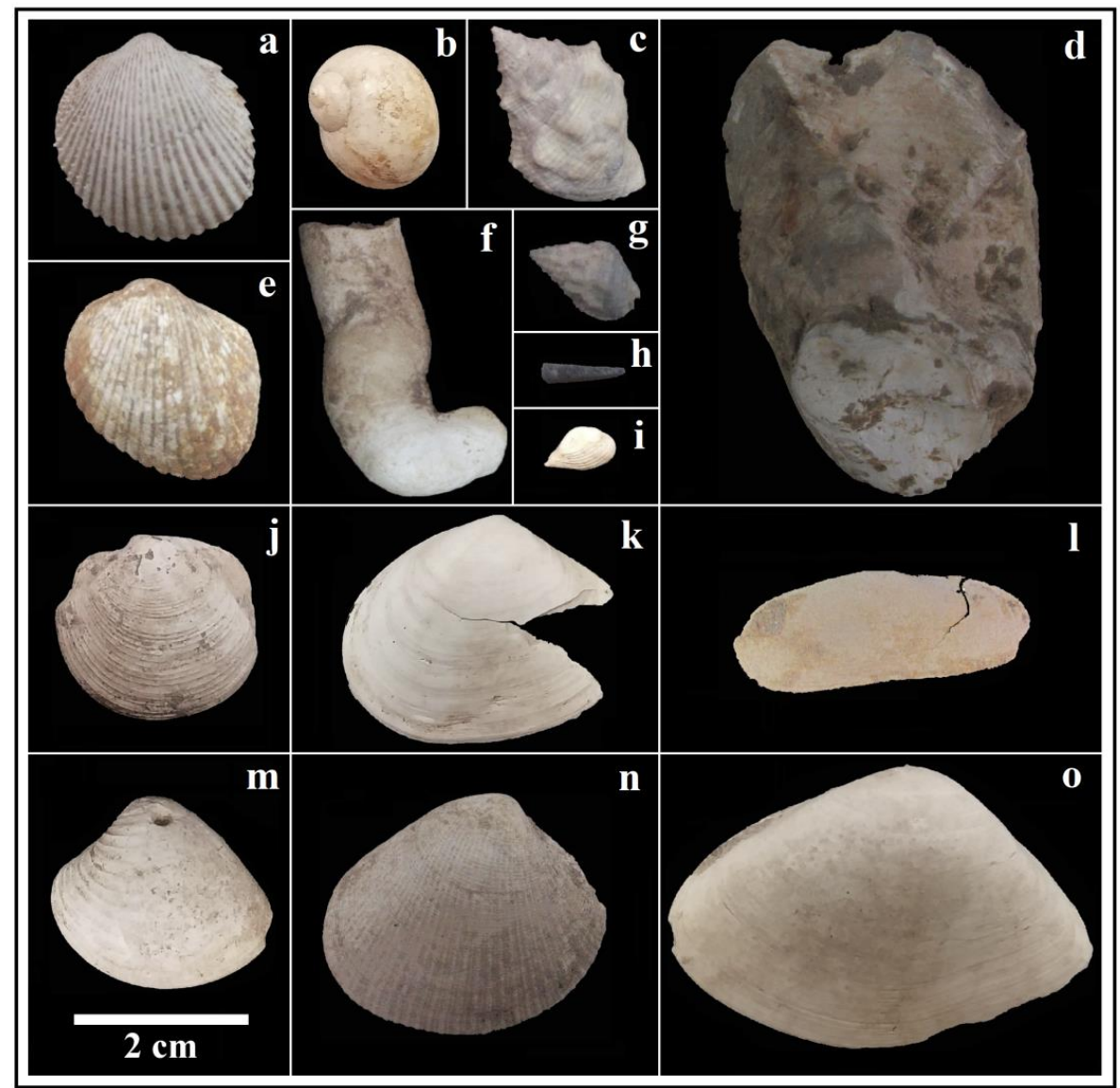

Figura 9 - Exemplares de diferentes taxa encontrados no afloramento; a- Trachycardium; b- Neritidae; c- Thaididae; d- Crassostrea; e- Dinocardium; f- Teredo; g- Nassariidae; h- Scaphopoda; i- Corbulidae; j- Lucina; k- Macoma; lTagelus; m- Anomalocardia brasiliana; n- Protothaca; o- Iphigenia.

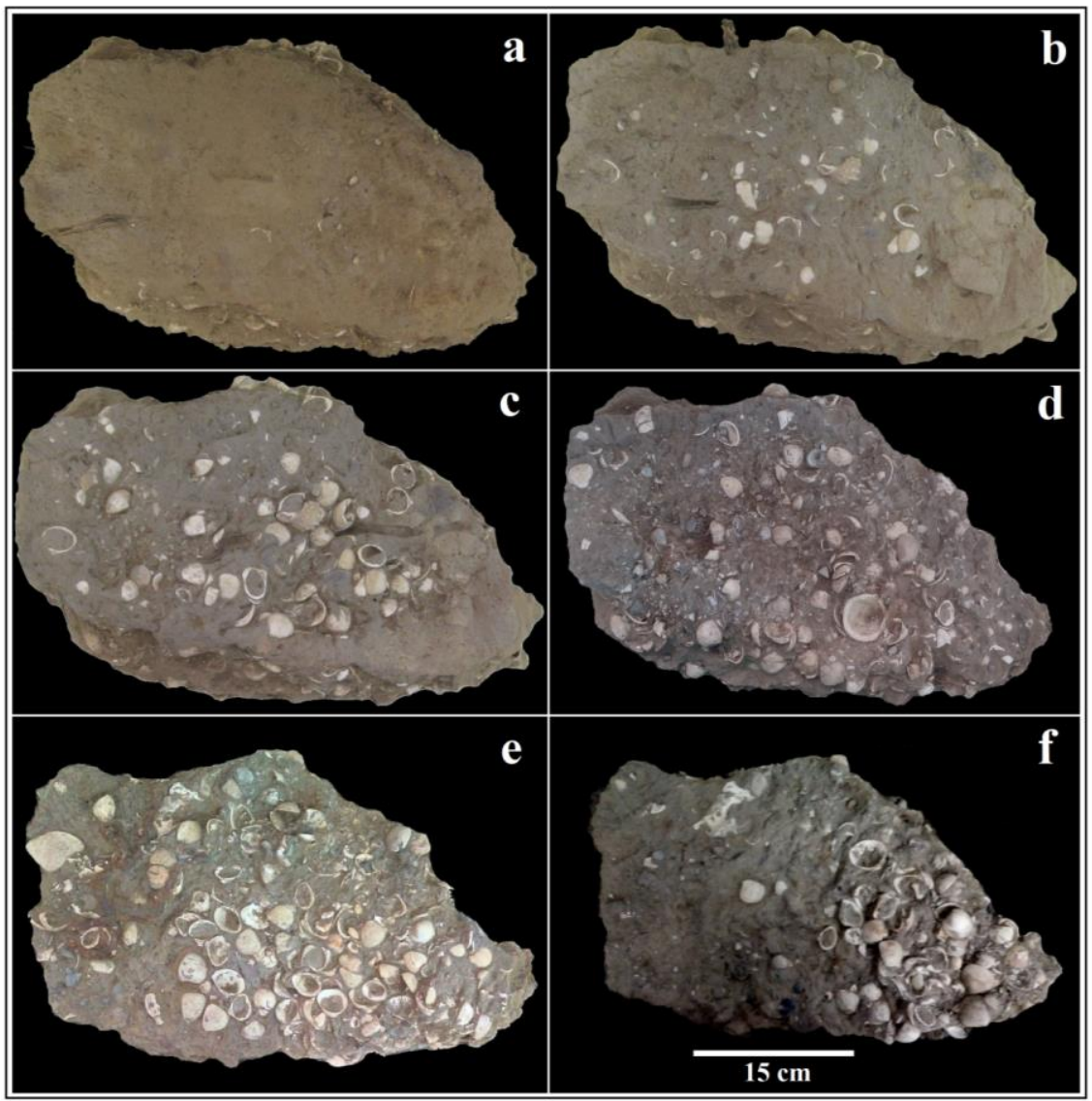

Figura 10 - Detalhes do Bloco original (a) e horizontes “descascados” (b; c; d; e; f). 


\section{DISCUSSÃO}

A identificação taxonômica das conchas de moluscos demonstrou a predominância de indivíduos da espécie Anomalocardia brasiliana. Segundo Angulo (1992) registros destes indivíduos podem indicar pelo menos o nível da maré baixa do local onde foram encontrados, caso os bioclastos apresentem aspectos que possam ser considerados como a preservação em posição de vida dos animais. As conchas de $A$. brasiliana encontram-se desarticuladas e apresentaram desgaste físico atuante em cerca de $90 \%$, sugerindo o transporte e o acúmulo em um nível estratigráfico diferente do original, ao invés da preservação em forma de vida (valvas articuladas), portanto, foram depositadas na margem do Rio Santo Antônio por forçantes hidrodinâmicas que os removeram de seu habitat convencional.

A disposição em planta das valvas e a ausência de uma orientação preferencial da concavidade dos bioclastos possibilitaram interpretar que o ambiente, onde os bioclastos foram depositados, era um ambiente raso e sofria com a ação de correntes com velocidades baixas. Esse processo de reorientação causado por correntes é bem explicado por Zabini (2011), onde as valvas de Lingulídeos encontradas no estudo foram acamadas em planta na forma de cordas e rosetas sugerindo a movimentação realizada por correntes de turbidez que mesmo sendo de baixas velocidades são capazes de revolver o material, em um processo chamado flutuação reversa.

Formações com acúmulos bioclásticos são recorrentes ao longo da Costa Brasileira. Cunha et al. (2012) descreve este tipo de material presente no rio Una no estado do Rio de Janeiro, onde a diversidade da malacofauna encontrada pelo autor apresentou similaridade com as encontradas no Rio Santo Antônio, em especial a presença das espécies Lucina pectinata, Crassostrea rhizophorae e a predominância amostral de conchas de Anomalocardia brasiliana. A geometria do depósito de conchas encontrado no terraço do Rio Santo Antônio também foi análoga a do acúmulo do rio Una. $\mathrm{Na}$ mesma região do rio Una, Martin et al. (1997) realizou algumas datações dos acúmulos através do método ${ }^{14} \mathrm{C}$ determinando uma idade de $6.610 \pm 230$ anos A.P, concluindo que a formação dos depósitos bioclásticos daquela localidade foi resultado da última transgressão marinha ocorrida no Holoceno.

Os aspectos tafonômicos dos bioclastos bem como a falta de conexão entre ambiente deposicional e os taxa indicam que esta localidade preserva condições ambientais imediatamente anteriores a grandes modificações geomorfológicas (e.g. Lima et al., 2006; Caron 2007; Lopes \& Buchmann, 2008).

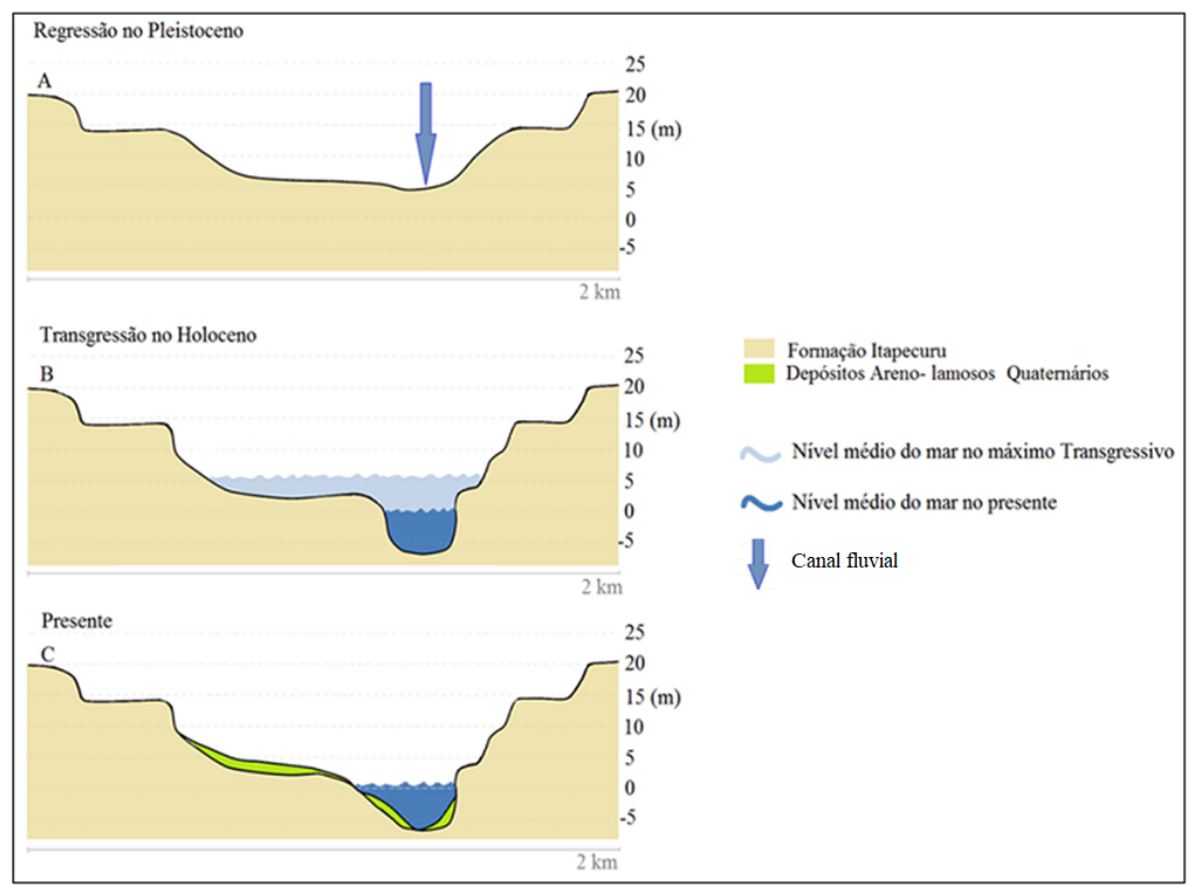

Figura 11 - Representação esquemática que sugere a sequência de eventos que resultaram na abertura do canal fluvial entre o Pleistoceno e o Holoceno no Rio Santo Antônio. 


\section{Reconstituição Paleoambiental}

A configuração geomorfológica do estuário do Rio Santo Antônio no Quaternário foi desenhada de acordo com as variações do nível do mar ocorridas ao longo do período. Durante o Pleistoceno (18.000 anos A.P.) a linha de costa regrediu posicionando o litoral próximo à quebra da plataforma na isóbata de $-130 \mathrm{~m}$ (Corrêa, 1995), o que sujeitava os ambientes emersos a processos erosivos (Soares Júnior, 2011). Estes processos provavelmente escavaram os sedimentos da Formação Itapecuru abrindo um vale inciso onde hoje é o Rio Santo Antônio (Figura 11).

Em decorrência da sobre-elevação do nível do mar aproximadamente em 5 metros acima do nível do mar atual por ocasião do máximo transgressivo do Holoceno, há 5.600 anos cal. A.P. (Medeanic \& Corrêa, 2010), ocorreu o afogamento das planícies fluviomarinhas, dando condições para a formação de lençóis de areia contendo fragmentos de conchas (Soares Júnior, 2011).
Neste tempo, devido à ausência do esporão arenoso (headlandspit) da praia de Panaquatira a desembocadura do Rio Santo Antônio era significativamente maior (Figura 12) e com o nível do mar sobre-elevado, os terrenos mais altos nas bordas do canal (Formação Itapecuru) foram impactados pela ação das ondas, esculpido terraços de abrasão marinha nas posições internas desta paleo-baía enquanto o material retirado das margens foi redepositado em maiores profundidades.

O recuo do nível do mar após o máximo transgressivo holocênico expôs enormes planícies de maré onde a vegetação de mangue encontrou condições ideais para se desenvolver, colonizando quase que por completo as áreas alagáveis ao longo do estuário. Este recuo do nível do mar em cerca de $1,4 \mathrm{~m}$ foi responsável pela ampliação da foz do Rio Santo Antônio culminando na formação do esporão arenoso de Panaquatira, o qual restringiu a hidrodinâmica do estuário expressando assim a conformidade atual do Rio Santo Antônio.

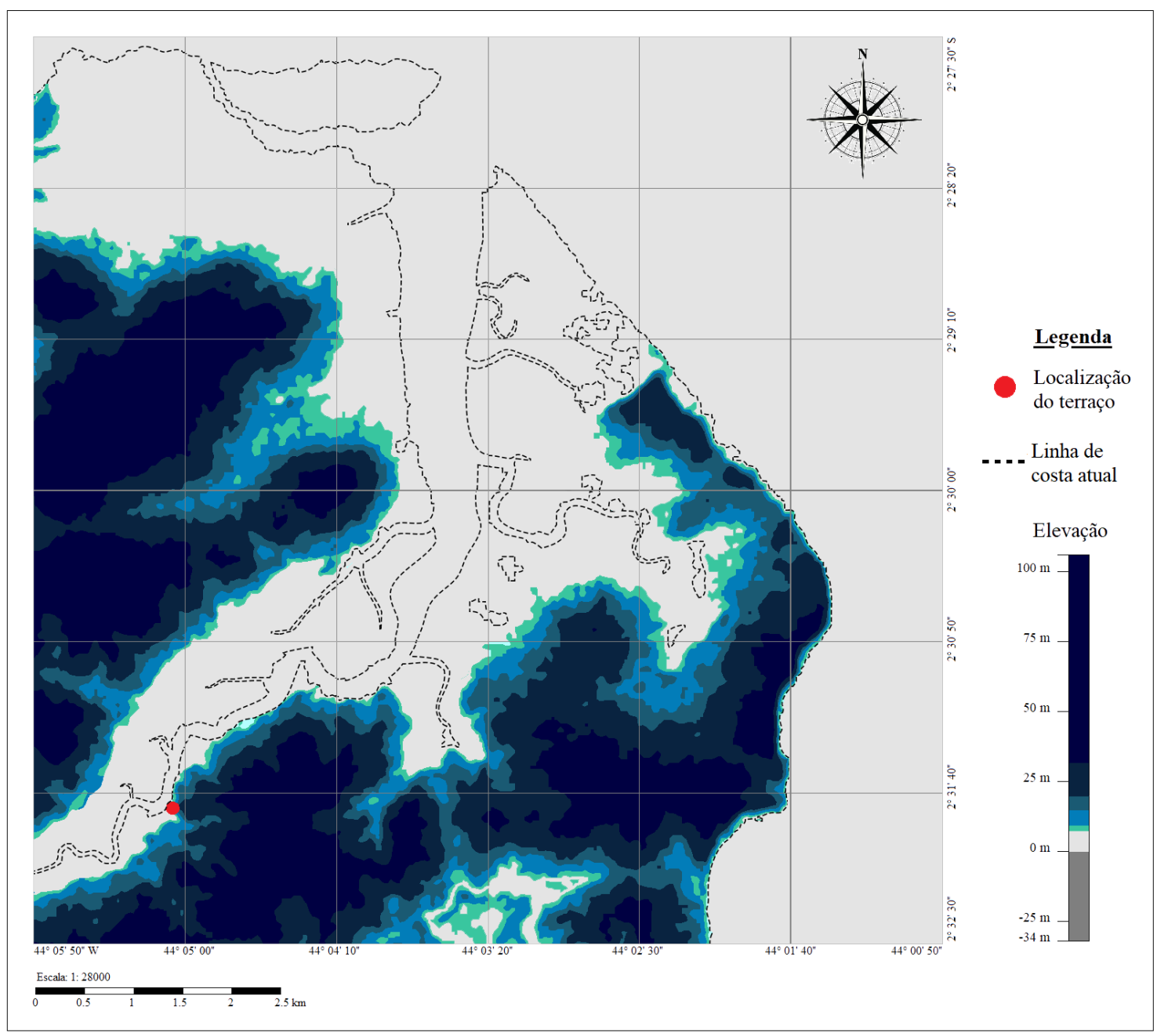

Figura 12 - Reconstituição da planície areno-lamosa formada no Holoceno no estuário do Rio Santo Antônio. 


\section{CONCLUSÕES}

Os estudos tafonômicos dos bioclastos encontrados no terraço as margens do estuário do Rio Santo Antônio sugeriram que o material foi depositado no presente local por forçantes hidrodinâmicas que os removeram de seu habitat convencional reposicionando-os sobre uma escarpa erosiva. A cota topográfica dos bioclastos indica o nível máximo da maré de sizígia equinocial desta localidade $(+3,2 \mathrm{~m})$, no entanto é a sua contextualização hidrodinâmica que possibilitou a reconstituição paleoambiental da localidade.
O paleonível encontrado na margem oeste do Rio Santo Antônio é, portanto, um indicativo de uma condição hidrodinâmica pretérita, provavelmente relacionada ao máximo transgressivo holocênico quando ainda não se fazia presente nesta região o esporão arenoso (headlandspit) da praia de Panaquatira. Nesta condição, a foz do Rio Santo Antônio era significativamente maior, permitindo um maior alcance de ondas ao interior do vale fluvial, que originou a concentração sedimentológica dos bioclastos.

\section{REFERÊNCIAS}

ABBOTT, R.T. American Seashells. Second Edition. New York: Van Nostrand Reinhold. 541 p., 1974.

ALMEIDA, H.G. Programa Levantamentos Geológicos Básicos do Brasil: São Luís SW/NW. 2000. Disp. em:<http://www.cprm.gov.br/publique/Geologia/GeologiaBasica/Projeto-Sao-Luis-NW\%7CSW-539. html>. Acesso em: 21 jan2016.

ÂNGUlO, R.J. Geologia da Planície Costeira do Estado do Paraná. São Paulo, 1992. 334 p. Tese de DoutoramentoInstituto de Geociências, Universidade de São Paulo.

BELKNAP, D.F. \& KRAFT, J.C. Influence of antecedent geology on stratigraphic preservation potential and evolution of delaware's barrier systems. Marine Geology, v. 62, p. 235$262,1985$.

BIGARELLA, J.J.; HARTKOPF, C.C.; SOBANSKI, A.; TREVISAN, N. Textura superficial dos grãos de areias e arenitos (contribuição à metodologia). Curitiba Archives of Biologyand Technology, v. 11, p. 253-275, 1955.

CALDAS, L.H.O.; STATTEGGER, K.; VITAL, H.. Holocene sea-level history and coastal evolution: evidences from coastal sediments of the northern Rio Grande do Norte Coast, $\mathrm{Ne}$ Brazil. Marine Geology, v. 228. p. 39-53, 2006.

CAMARGO, M.G. SYSGRAN - Análises e gráficos sedimentológicos. Centro de Estudos do Mar, Universidade Federal do Paraná, 2006. Versão 3.0. Disp. em <http://www.cem.ufpr/sysgran>. Acesso em: 01abr2016.

CARON, F. Depósitos sedimentares associados à desembocadura do Arroio Chuí (Planície Costeira do Rio Grande do Sul e suas relações com as variações do nível do mar durante o Holoceno. Porto Alegre, 2007, 81 p. Dissertação (Mestrado Geociências) - Universidade Federal do Rio Grande do Sul.

CARON, F.; TOMAZELLI, L.J.; LIMA, L.G.; BARBOZA, E.G.; ROSA, M.L.C.C.; DILLENBURG, S.R. Características Estratigráficas da Barreira Transgressiva Holocênica na Praia dos Concheiros, Planície Costeira do Rio Grande do Sul. In: CONGRESSO ESTUDO DO QUATERNÁRIO, XIII, 2011, Armação de Búzios. Anais...Armação de Búzios: Associação de Estudo do Quaternário.

CORRÊA, I.C.S., MARTINS, L.R., KETZER, J.M., ELIAS, A.R.D. A Plataforma Continental Sul e Sudeste Brasileira Durante O Holoceno. In: CONGRESSO LATINOAMERICANO DE CIENCIAS DEL MAR, VII, Mar del Plata-Argentina, 1995. Anais...Mar del Plata: v. 1, p. 56,

COWELL, P.J., \& THOM, B.G. Morphodynamics of coastal evolution. In: R. W. G. Carter, \& C. D. Woodroffe, (Eds), Coastal evolution, late Quaternary shoreline morphodynamics. Cambridge: Cambridge University Press, p. 33-40, 1994.
COWELL, P.J., ROY, P.S., CLEVERINGA, J. e DE BOER, P.L. Simulating coastal systems tracts using the ShorefaceTranslation Model, International Association of Sedimentologists Special Publication, Oxford, Blackwell Scientific Pub, v. 62, p. 165-175, 1999.

CUNHA, A.M.; CASTRO, J.W.A.; DIAS, F.F. A importância da preservação das acumulações bioclásticas da planície costeira do rio una, municípios de Cabo Frio e Armação Dos Búzios, RJ, Brasil. Anuário do Instituto de Geociências, UFRJ, v. 35, p. 58-67, 2012.

CURRAY, J.R. Transgressions and Regressions. Marine Geology - Shepard Commemorative Volume, New York, p. 175-203, 1964.

CURRAY, J.R.; EMMEL, F.J.; CRAMPTON, P.J.S. Holocene History of a Strandplain, Lagoonal Coast, Nayariti, Mexico. In: COSTOUARES, A.A.; PHELGER, V.B. (Eds). Lagunas Costeras-. Univ. NationalAutonoma do Mexico, p. 64-100, 1969.

FEITOSA, A.C. A zona costeira e o litoral na ilha do maranhão, Estado do Maranhão- Brasil. 2013. 12p. Disp. em: <https://pt.scribd.com/doc/138629108/Antonio-CordeiroFeitosa>. Acesso em: 20 jan 2016.

FLEXOR, J.M.; SUGUIO, K.; BITTENCOURT, A.C.S.P.; VILAS-BOAS, G.S. Le Quaternaire Marin Brésilien (Littoral pauliste, Sud fluminense et bahianais). Cahier Orstom Série Géologie, Paris, França, v. 11, n.1, p. 95-124, 1979.

FOLK, R.L. \& WARD, W.C. Brazos River bar: a study in the significance of grain size parameters. Journal of Sedimentary Petrology, v. 27, p. 3-26, 1957.

HOLZ, M. \& SIMÕES M.G. Elementos Fundamentais de Tafonomia. Porto Alegre: Editora UFRGS, 231 p, 2002.

KRUMBEIN, W.C. Measurements and geologic significance of shape and roundness of sedimentary particles. Journal of Sedimentary Petrology. v.11, p. 64-72, 1941.

LIMA, L.G.; LOPES, R.P.; CARON, F.; BUCHMANN, F.S.C. Um Novo Afloramento Contendo Fósseis de Vertebrados Pleistocênicos na Planície Costeira do Rio Grande do Sul. In: SIMPÓSIO BRASILEIRO DE PALEONTOLOGIA DE VERTEBRADOS, V, 2006, Santa Maria. Revista Ciência e natura. Santa Maria: Universidade Federal de Santa Maria, p. 78-78, 2006

LOPES, R.P. \& BUCHMANN, F.S.C. Comparação tafonômica entre duas concentrações fossilíferas (shellbeds) da Planície Costeira do Rio Grande do Sul, Brasil, Journal of Geoscience, v. 4, p. 65-77, 2008.

MARTIN, L.; SUGUIO, K.; DOMINGUEZ, J.ML; FLEXOR, J.M. Geologia do Quaternário costeiro do litoral norte do Rio de Janeiro e do Espírito Santo. CPRM/FAPESP, Belo Horizonte - MG, 112 p, 1997. 
MEDEANIC, S. \& CORRÊA, I.C.S. Climatic changes in the coastal plain of the Rio Grande do Sul state in the Holocene: palynomorph evidences. Pan-American Journal of Aquatic Sciences, v. 5, p. 287-297, 2010.

MEIRELES, A.J.A.; ARRUDA, M.G.C.; GORAYEBE, A.; THIERS, P.R.L. Integração dos indicadores geoambientais de flutuação do nível relativo do mar e de mudanças climáticas no litoral Cearense. Mercator, v. 8, p. 109-134, 2005.

MUNSELL Color. Geological Rock-Color Charts with genuine Munsell color ships. Munsell Color X-rite. Grand Rapids, MI, USA. 2009.

PEREIRA, E.D. Avaliação da vulnerabilidade natural à contaminação do solo e do aquífero do reservatório Batatã - São Luís (MA). Rio Claro. 2006. 174 p. Tese (Doutorado em Geociência) -Universidade Estadual Paulista.

PEREIRA, E.D. \& ZAINE, J.E. Mapa geológico-geotécnico da bacia do rio Bacanga - São Luís (Ma). Geociências, v. 26, $\mathrm{n}$. 1, p. 45-54, 2007.

PONCIANO, L.C.M.O. Tafonomia de invertebrados: $O$ enigma das conchas. In: SOARES. M.B. (Org.). A paleontologia na sala de aula. 1ed. Ribeirão Preto: Sociedade Brasileira de Paleontologia, v. 1, p. 273-294, 2015.

RITTENHOUSE, G. A visual method of estimating two dimensional sphericity. Journal of Sedimentary Petrology. v. 13, n. 2, p. 79-81, 1943.

RODRIGUES, T.L.N.; ARAÚJO, C.C.; CAMOZZATO, E.; RAMGRAB, G.E. (Orgs.) São Luís, Folha SA-23-2-A, Cururupu Folha SA-23-X-C, escala 1:250.000. Brasília: Companhia de Pesquisa de Recursos Minerais, Programa de Levantamentos Geológicos Básicos do Brasil, 185 p, 1994.

ROY, P.S.; COWELL, P.J.; FERLAND, M.A.; THORN, B.G. Wave-dominated coasts. In: CARTER, R.W. G. \& WOODROFFE, C.D. (ed.). Coastal evolution Late Quaternary shoreline morphodynamics. Cambridge, Cambridge University Press, p.121-186, 1994.
SANTOS, J.H.S.; TAROUCO, J.E.F.; SOUZA, B.B.Q.; MOCHEL, F.R. Características geológicas e geomorfológicas da Baia de São Marcos, Golfão Maranhense- MA. In: SIMPÓSIO NACIONAL DE GEOMORFOLOGIA, IV, 2004, São Luís. Anais... São Luís-MA. Geomorfologia: interfaces, aplicações e perspectivas., v. 2. p. 1-7, 2002.

SOARES JÚNIOR, A.V.; HASUI, Y.; COSTA, J.B.S.; MACHADO, F.B. Evolução do rifteamento e Paleogeografia da Margem Atlântica Equatorial do Brasil: Triássico ao Holoceno. Geociências, v. 30, p. 370-390, 2011.

SUGUIO, K. Introdução a sedimentologia. São Paulo. Ed. Edgard Blucher. EDUSP, 317 p., 1973.

THOM, B.G. \& ROY, P.S. Sea-level change in New South Wales over the past 15,000 years. In: HOPLEY, D. (ed). Australian sea levels in the last 15,000 years: a review. Geography Department, James Cook University of North Queensland, Monograph Series, Occasional Paper 3, pp. 6484, 1983.

VEIGA JÚNIOR, J.P. Carta geológica. CPRM, Folha SA. 23X/Z SÃO LUÍS NE/SE. Escala 1:500.000. Recife: 2000.

WETZEL, R.G. Limnologia. BOAVID, M.J. (Ed). Fundação Calouste Gulbenkian. Limnology. 2nd ed. 1983. Philadelphia: Saunders College, 760 p, 1993.

ZABINI, C. Integração da tafonomia e estratigrafia de sequências no estudo dos lingulídeos da sucessão devoniana da Bacia do Paraná. Porto Alegre, 2011. 240 p. Tese (Doutorado em Geociências). Universidade Federal do Rio Grande do Sul. 